\title{
Greasing the Wheels: Pork and Public Goods Contributions in a Legislative Bargaining Experiment*
}

\author{
Nels Christiansen ${ }^{\dagger}$ \\ Trinity University \\ Department of Economics
}

06 October 2015

\begin{abstract}
When a legislature bargains over funds for pork and public goods, and the funds come from a common budget, increased spending on the public good means greater payoff equality since it comes at the expense of pork. This paper explores whether inequity aversion then leads to greater public goods spending. Using both theory and a laboratory experiment we show inequity aversion generally decreases inequity within a coalition by limiting proposer power. However, this does not always mean greater public goods contributions because the types of proposals passed change in equilibrium. In addition, the experiment investigates the theoretical prediction that increasing players' relative preference for pork can increase public goods contributions. We show that while average public goods contributions remain unchanged, there is evidence at the individual level that subjects hold out for higher public goods contributions as predicted.
\end{abstract}

JEL classification: D72, C52, C7, C92

Keywords: legislative bargaining, public goods, pork, inequity aversion

\footnotetext{
*I received valuable comments from John Kagel, Alan Wiseman, Massimo Morelli, Paul J. Healy, Jim Peck, Mark Schelker, Marina Agranov, Christoph Vanberg, the editor and referees, and seminar participants at the Western Economic Association International and Public Choice Society meetings. Financial support from the National Science Foundation Grant No. 0519205 and from the Mershon Center at The Ohio State University is gratefully acknowledged. Any opinions or findings in this paper are those of the author and do not necessarily reflect the views of the funding agencies.

${ }^{\dagger}$ Department of Economics, Trinity University, One Trinity Place, San Antonio, TX 78212, USA; Tel. +1 (210) 999-8252; nels.christiansen@trinity.edu.
} 


\section{Introduction}

Legislatures are often tasked with bargaining over public goods, which benefit everyone, and private goods ("pork"), which only benefit the legislator to which they are allocated. Public good provision is one of the primary roles of the legislature so that understanding what affects the division of funds between pork and public goods is an important question. To that end, this paper uses theory and an experiment to explore separately the effects of inequity aversion and relative preferences for pork among legislators on the division of a budget between pork and public goods. What is particularly interesting is that the effects of both are often counterintuitive.

There is good reason to think that inequity aversion might influence legislative bargaining. Not only might legislators themselves care about the payoffs to other legislators from a bill, but inequity averse constituents would likely produce inequity averse legislators if voters turn on legislators who bring too little funding home in comparison to other districts. ${ }^{1}$ When funds for pork and public goods come from a common budget, increased contributions to the public good will mean decreased contributions to pork and greater payoff equity among legislators. Do social preferences then limit pork spending and decrease payoff inequity?

The theoretical literature on legislative bargaining suggests that the answer is not as straightforward as it might seem. Montero (2007) incorporates inequity aversion as formalized in Fehr and Schmidt (1999) into the Baron and Ferejohn (1989) "divide the pie" bargaining game. The paper shows that inequity aversion is likely to increase payoff inequity between players by increasing the payoff of the proposer. Whether the theoretical increase in proposer power extends to bargaining in the presence of a public good and might allow a proposer who prefers pork more proposal power is an open question.

To explore these ideas, we use the legislative bargaining model in Volden and Wiseman (2007), which is an extension of the Baron-Ferejohn model to include a public good whose funding is constrained by pork allocations. Assuming legislators have heterogenous preferences for pork and public goods, and pork and public goods spending come from a common budget, we extend the literature in two ways. First, we incorporate Fehr-Schmidt inequity averse preferences and solve the bargaining model for a handful of parameter values. We utilize a laboratory experiment to evaluate whether behavioral patters, especially pork and public goods contributions, are consistent with the point predictions of the model. The paper shows that inequity aversion in the presence of a public good is generally predicted to decrease the power of the proposer, and the experimental results closely coincide with the predictions. This does not always mean higher contributions to the public good, however.

\footnotetext{
${ }^{1}$ In the U.S. the large inequities surrounding per-capita pork spending, where states such as Alaska receive far more money than most others, have recently garnered negative attention.
} 
We show in both theory and in the experiment that inequity aversion can increase pork spending because the types of proposals passed change in equilibrium.

The Volden-Wiseman model predicts that changes in the preference for pork will also matter for public good provision. That is, increasing the preference for pork can increase contributions to the public good. ${ }^{2}$ In a recent experimental paper examining this prediction when legislators have homogenous preferences for pork and public goods, Fréchette et al. (2012) find that that public goods contributions decrease as the relative value for pork rises. We simplify the choice facing subjects in the experiment by holding constant the marginal return on the public good as the preference for pork rises, and we find no change in the amount given to the public good. Moreover, we do find at the individual level that subjects are holding out for higher public goods contributions as predicted. This fails to increase the average amount contributed because not all votes are needed to pass a proposal, and some subjects continue to accept the same public goods contribution as before the change in preference for pork.

The tension between funding pork and public goods appears in other models. Tergiman (2015) shows within a legislative bargaining framework that when the ruling coalition can tie a spending bill to a vote of confidence procedure, the latter strengthens a proposer's power and reduces funding for the public good. Lizerri and Persico (2001) consider national candidates making binding promises about pork and public goods spending and compare contributions under a winner-take-all system to a proportional system. Battaglini et al. (2012) and Battaglini et al. (2014) explore public good provision in a dynamic environment. We focus on the the Volden-Wiseman model because it is a static model with a single decision, which provides a straightforward environment to examine the effects of inequity aversion on public good provision.

The paper is also part of a growing experimental literature on legislative bargaining, which has focused on purely distributive games in which funding is allocated to goods that only benefit the recipient. ${ }^{3}$ Jackson and Moselle (2002) extend the Baron-Ferejohn model to include a uni-dimensional policy in addition to the distributive good with legislators having heterogeneous preferences over each. ${ }^{4}$ Christiansen et al. (2014) find support for the paper's comparative statics predictions, including the ability of pork to create coalitions of

\footnotetext{
${ }^{2}$ Decreasing the relative value of the public good means higher contributions to it are necessary to secure the votes of players who would prefer to receive pork.

${ }^{3}$ The majority of research has studied the Baron-Ferejohn legislative bargaining model. McKelvey (1991), Diermeier and Morton (2005), Fréchette et al. (2003), Fréchette et al. (2005a), and Fréchette et al. (2005b) experimentally examine various predictions of the model including the effects of open and closed amendment rules, changing proposal recognition probabilities, and contrasting the comparative statics results of the model to other models of the legislative bargaining process.

${ }^{4}$ In their model funds allocated to pork do not constrain the policy choice since policy is not in a monetary dimension. The funds for pork come from an exogenous budget, and this budget will always be completely spent in equilibrium.
} 
"strange bedfellows." However, it shows that coalition members opt for an "efficient equal split" of payoffs rather than the stationary subgame perfect equilibrium prediction. ${ }^{5}$

The paper proceeds as follows. Section 2 details the legislative bargaining model in which preferences for pork are heterogeneous. Section 3 describes the experimental design. The results of the experiment are in Section 4 with a discussion of the results and their implications in Section 5.

\section{Theory}

\subsection{The Bargaining Model}

In the Volden-Wiseman bargaining model (hereafter VW) $n$ legislators bargain over pork and public goods ( $n$ is odd). In the heterogeneous preference case legislators either have a high taste for pork spending (type $H$ ) or a low taste for pork (type $L$ ). We use feminine pronouns when referring to type $H$ and masculine pronouns when referring to type $L$.

Let $\alpha^{H}$ and $\alpha^{L}$ be the marginal utilities of pork for $H$ and $L$, respectively, and $q$ the marginal utility for the public good. We assume $\alpha^{L}<q<\alpha^{H}$ and that the marginal utilities remain constant. Utility is assumed to be separable and for legislator $i$ is given as,

$$
U_{i}\left(x_{i}, y, \theta\right)=\alpha^{\theta} x_{i}+q y
$$

where $x_{i}$ is the amount of pork allocated to $i, y$ is the contribution to the public good, and $\theta \in\{H, L\}$ is the legislator's type. Let $m$ and $n-m$ be the number of $L$ and $H$ legislators, respectively. The legislature has a fixed budget of $\$ 1$ and spending must satisfy budget balance so that $y+\sum_{i=1}^{n} x_{i} \leq 1$.

Legislative proposals are made according to a random recognition rule formulated by Baron and Ferejohn (1989). Legislator $i$ is randomly chosen to make a proposal $\Psi_{i}=$ $\left(x_{i}^{1}, x_{i}^{2}, \ldots, x_{i}^{n}, y_{i}\right)$ that divides the budget in the form of pork projects to up to $n$ districts and places the remainder in the public good. All players have an equal chance at being chosen as proposer. After submitting the proposal, $\Psi_{i}$ is then brought to a vote, and if a majority of legislators support the bill it passes. If not, the game continues to the next stage in which a new proposer is randomly chosen. To incorporate time discounting all legislators are assumed to have a common, constant discount factor, $0 \leq \delta \leq 1$, between bargaining stages. As written the model has multiple Nash equilibria which are based on

\footnotetext{
${ }^{5}$ Christiansen and Kagel (2015) extend these results using a new treatment to look at whether bargaining outcomes differ when legislators bargain over the policy and cuts to private goods (i.e., players bargain over tax burdens instead of tax benefits). They find that even bargaining over cuts to private goods speeds the time to agreement in relation to bargaining without private goods, but cuts are less effective than when private goods are handed out.
} 
complex future play when the current proposal is rejected. To narrow the set of possible equilibria the solution concept used for the bargaining model is stationary subgame perfect Nash equilibrium (SSPE). ${ }^{6}$

The SSPE to the bargaining game includes a handful of cases and is not presented here. Instead, we refer the reader to the complete characterization of the equilibrium provided in Volden and Wiseman (2007), Volden and Wiseman (2008), and Christiansen (2013) along with the functional forms for the equilibrium allocations. The equilibrium depends on $m$ and the relative preference for pork for $H, \alpha^{H} / q$. It is important to note two things: (i) No pork will be allocated to type $L \mathrm{~s}$ in equilibrium. Contributions to the public good give them higher marginal utility and result in increased utility to every other player. As such, $\alpha^{L}$ plays no role in the equilibrium analysis. (ii) There is no delay in passing legislation in equilibrium. Because proposers give coalition members their continuation values (but generally no more), proposals are always approved in the first stage.

\subsection{Preferences with Inequity Aversion}

The SSPE of the bargaining game often specifies vastly different payoffs, even across players in the winning coalition. To account for potential fairness concerns we extend the model to consider preferences as in Fehr and Schmidt (1999). Utility is given by,

$$
\tilde{U}_{i}\left(x_{i}, y, \theta\right)=U_{i}-\frac{a_{i}}{n-1} \sum_{j \neq i} \max \left\{U_{j}-U_{i}, 0\right\}-\frac{b_{i}}{n-1} \sum_{j \neq i} \max \left\{U_{i}-U_{j}, 0\right\},
$$

where $U_{i}$ is utility in the VW model, $a_{i}$ measures the disutility from receiving a lower payoff than other players ("disadvantageous inequality"), and $b_{i}$ measures the disutility from a higher payoff than other players ("advantageous inequality"). Assume $a_{i} \geq b_{i}$ and $0 \leq b_{i}<1 .^{7}$ We restrict our analysis to $a_{i}=a_{j}=a$ and $b_{i}=b_{j}=b$ for all $i, j$, and given the intractability of the functional forms, we generally solve for the equilibrium by holding either $a$ or $b$ constant and varying the other parameter.

\section{Experimental Design}

The paper reports the results of two treatments. The first treatment examines the predictions when $H$ 's preference for pork is strong, and the second treatment when the preference is weak. When the preference for pork is strong both pork and public good are funded by

\footnotetext{
${ }^{6}$ See Baron and Ferejohn (1989) for a thorough discussion of stationary equilibria and the degree to which they are appropriate in this environment.

${ }^{7}$ For this range of $b_{i}, i$ is prepared to reduce her own payoff to increase $j$ 's payoff. $b=1$ implies she would sacrifice her own utility without any corresponding increase in $U_{j} . b_{i}<0$ implies a player gets extra utility from having a higher payoff than others.
} 
both types of proposers in the SSPE. This creates unequal payoffs across players and opens up the possibility that proposers will respond by allocating more funding to the public good. When the preference for pork is weak, $H$ proposers use the public good to gain support for their proposal, and changing the relative preference for pork allows for testing the main comparative statics prediction of the VW model. Because the marginal utility for pork for $L$ s does not play a role in the equilibrium analysis, it is held fixed in both treatments. The players' marginal utility for the public good, too, is held constant because only the relative magnitude of $\alpha^{H}$ versus $q$ affects the equilibrium. In what follows $\alpha^{L}$ and $q$ are given as 0.14 and 0.20 , respectively. The discount rate is set to $\delta=0.8$, and the size of the legislature is $n=5$ players. Both values are consistent with previous experiments of VW's homogenous preference case, and it facilitates easy comparisons between the results. The budget to be divided is 50 experimental currency units (ECUs).

\subsection{Strong Treatment}

In the strong treatment $\alpha^{H}=1.5$ and $m=2$ so that the model predicts an $L$ proposer must use pork to obtain the vote of one $H$ to pass a bill geared towards the public good. ${ }^{8}$ We denote this type of proposal by $L_{y} L_{y} H_{x y}$ where the first entry denotes the proposer's type and the remaining entries specify which players vote to approve the proposal. The subscripts denote how each player's payoff is determined: from only the public good, $y$, from only pork, $x$, or from both pork and public good, $x y$. An $H$ proposer has two competing options in making her proposal. First, she could attempt to allocate enough to the public good to get the $L \mathrm{~s}$ ' support and keep the remainder for herself in pork, $H_{x y} L_{y} L_{y}$. Second, she could form a minimum-winning coalition of three $H$ s (herself included) using only pork and leave nothing for the public good, $H_{x} H_{x} H_{x}$. In equilibrium the proposer mixes over these two types of proposals so that with positive probability an $H$ proposer who cares relatively little for the public good allocates funds to it anyway to win $L$ votes. ${ }^{9}$

The predictions appear in Table 1 . Note that the $H$ proposer is more likely to propose to type $L$ than to form a coalition with the other type $H$ s. However, the payoff discrepancy in the coalition with type $L$ is extremely large. An $L$ proposer comes close to being able to pass $y=50$, but even when he allocates 2.8 experimental currency units (ECUs) in pork to one type $H$, it leads to a payoff difference of over $\$ 4$.

As shown in the Appendix, modifying preferences to include inequity aversion does not

\footnotetext{
${ }^{8}$ If $m>2$ type $L$ s have a majority and can easily pass $y=50$. The same proposal is predicted by the model if $\alpha^{H}$ is not sufficiently large.

${ }^{9}$ The equilibrium as it appears in VW incorrectly describes a pure strategy for $H$ proposers in which they form only $H_{x} H_{x} H_{x}$ coalitions using pork. The problem with this is that it guarantees the $L \mathrm{~s}$ a low continuation value for the game which can be exploited by an $H$ proposer. See Christiansen (2013) for details.
} 
Table 1. SSPE for the Strong treatment

\begin{tabular}{|c|c|c|c|c|c|c|c|c|}
\hline \multirow[b]{2}{*}{$\begin{array}{l}\text { Proposer } \\
\text { Type }\end{array}$} & \multirow[b]{2}{*}{$\begin{array}{c}\text { Winning } \\
\text { Coalition }^{a}\end{array}$} & \multirow[b]{2}{*}{$\begin{array}{l}\text { Mixing } \\
\text { Prob. }\end{array}$} & \multicolumn{3}{|c|}{ Budget Allocation (ECUs) } & \multicolumn{3}{|c|}{$\$$ Payoffs } \\
\hline & & & $\begin{array}{l}\text { Public } \\
\text { Good }\end{array}$ & $\begin{array}{l}\text { Pork to } \\
\text { Proposer }\end{array}$ & $\begin{array}{l}\text { Pork to } \\
\text { Partners }\end{array}$ & Proposer & $\begin{array}{l}H \text { Partner } \\
\text { with Pork }\end{array}$ & $\begin{array}{c}\text { All } \\
\text { Others }\end{array}$ \\
\hline \multirow{2}{*}{$H$} & $H_{x y} L_{y} L_{y}$ & 0.59 & 21.0 & 29.0 & 0 & 47.63 & - & 4.21 \\
\hline & $H_{x} H_{x} H_{x}$ & 0.41 & 0 & 31.8 & 18.2 & 47.63 & 13.68 & 0 \\
\hline$L$ & $L_{y} L_{y} H_{x y}$ & 1.0 & 47.2 & 0 & 2.8 & 9.43 & 13.68 & 9.43 \\
\hline
\end{tabular}

Note: Predictions are for $n=5, \delta=0.8, \alpha_{L}=0.14, q=0.20$, and $\alpha^{H}=1.50$.

${ }^{a} \mathrm{~A}$ member of the winning coalition votes in favor of the proposal.

affect the types of proposals offered in the SSPE so long as $a$ and $b$ are small. An $L$ proposer still offers $L_{y} L_{y} H_{x y}$, but the contribution to the public good rises in equilibrium as $a$ and $b$ increase. This is because as $a$ increases, the $H$ receiving pork is hesitant to turn it down and risk not receiving pork in the next stage since that means a lower payoff than another player. As $b$ increases the attractiveness of being chosen proposer declines along with $H$ 's continuation value. Once $a$ and/or $b$ gets large enough the $L$ proposer is able to fully fund the public good.

An $H$ proposer still mixes over $H_{x} H_{x} H_{x}$ and $H_{x y} L_{y} L_{y}$, but the probability of making the former proposal rises in equilibrium as $b$ increases. A higher $b$ lowers $H$ 's continuation value while leaving $L$ 's unchanged since he never receives a higher payoff than other players, making an $H_{x} H_{x} H_{x}$ proposal more attractive. The relationship with $a$ is more subtle-the probability of offering $H_{x} H_{x} H_{x}$ rises as $a$ increases when $L$ proposes $y<50$ and falls otherwise-but the bottom line is that the probability of $H_{x} H_{x} H_{x}$ is always greater than in the model without inequity aversion.

As $a$ increases an $H$ proposer receives less pork regardless of the equilibrium proposal she makes since coalition members dislike large payoffs for the proposer. ${ }^{10}$ As $b$ increases the proposer receives less pork in an $H_{x} H_{x} H_{x}$ proposal but more in an $H_{x y} L_{y} L_{y}$ proposal. With respect to the latter proposal, a higher $b$ makes it more likely an $H_{x} H_{x} H_{x}$ proposal is offered thereby increasing the chance an $L$ gets a zero payoff in the next stage. While this allows the proposer to achieve a higher payoff, note that $H_{x y} L_{y} L_{y}$ is offered less frequently as $b$ increases.

To summarize, in the Strong treatment inequity aversion predicts (i) an $L$ proposer is able to provide more public good than predicted under the SSPE, and may be able to fully

\footnotetext{
${ }^{10}$ The idea is that increasing $a$ also decreases coalition members' continuation values, but the value of the equilibrium proposal falls faster. The proposer must then respond by taking less.
} 
Table 2. SSPE for the Weak treatment

\begin{tabular}{|c|c|ccc|ccc|}
\hline \multicolumn{9}{|c|}{$\alpha^{H}=0.3$} \\
\hline \hline \multirow{3}{*}{$\begin{array}{c}\text { Proposer } \\
\text { Type }\end{array}$} & $\begin{array}{c}\text { Winning } \\
\text { Coalition }\end{array}$
\end{tabular}

\begin{tabular}{|c|c|ccc|ccc|}
\hline \multicolumn{10}{|c|}{$\alpha^{H}=0.6$} \\
\hline \hline \multirow{2}{*}{$\begin{array}{c}\text { Proposer } \\
\text { Type }\end{array}$} & $\begin{array}{c}\text { Winning } \\
\text { Coalition }\end{array}$ & $\begin{array}{c}\text { Budget Allocation (ECUs) } \\
\text { Public } \\
\text { Good }\end{array}$ & $\begin{array}{c}\text { Pork to } \\
\text { Proposer }\end{array}$ & $\begin{array}{c}\text { Pork to } \\
\text { Partners }\end{array}$ & Proposer & $\begin{array}{c}H \text { Partner } \\
\text { with Pork }\end{array}$ & $\begin{array}{c}\text { All } \\
\text { Others }\end{array}$ \\
\hline$H$ & $H_{x y} H_{x y} L_{y}$ & 22.2 & 23.4 & 4.5 & 18.44 & 7.11 & 4.44 \\
\hline$L$ & $L_{y} H_{y} H_{y} H_{y} H_{y}$ & 50 & 0 & 0 & 10.00 & - & 10.00 \\
\hline
\end{tabular}

Note: Predictions are for $n=5, \delta=0.8, \alpha_{L}=0.14, q=0.20$, and $m=1$.

${ }^{a} \mathrm{~A}$ member of the winning coalition votes in favor of the proposal.

fund the public good, (ii) an $\mathrm{H}$ proposer is more likely to offer an $H_{x} H_{x} H_{x}$ proposal, and she takes less in pork for herself than predicted under the SSPE, (iii) an $H$ proposer takes less pork than predicted in an $H_{x y} L_{y} L_{y}$ proposal so long as $a$ is large enough and/or $b$ is small. With the possible exception of (iii), all of these imply lower payoff inequity between the proposer and coalition members.

\subsection{Weak Treatment}

The Weak preference for pork treatment utilizes a crossover design: it fixes $m=1$ and allows $\alpha^{H}$ to vary between 0.3 and 0.6 in early and late bargaining rounds. The model predicts that $L$ proposers should still be able to pass fully-funded public goods bills without the need for pork for both values of $\alpha^{H}$. In the SSPE $H$ proposers use the public good to gain support for a proposal when $\alpha^{H}=0.3$. The proposer contributes enough to the public good to satisfy the other $H$ players' continuation value for the game (and hence also satisfy the $L$ player's continuation value) and keeps the rest of the budget for herself in pork, $H_{x y} H_{y} H_{y} H_{y} L_{y}$. When $\alpha^{H}=0.6 \mathrm{H}$ s require a larger public goods allocation to satisfy their continuation value. An $H$ proposer responds by contributing enough to the public good to get the $L$ player's support, contributing pork to one other $H$, and keeping the rest in pork for herself, $H_{x y} H_{x y} L_{y}$. Table 2 details the theoretical predictions.

The types of proposals offered in equilibrium are unchanged for the values of $a$ and 
$b$ considered in the Appendix when $\alpha^{H}=0.3$. The only difference is that an $H$ proposer contributes more to the public good as $a$ increases but less as $b$ increases. A higher $a$ sharply reduces a coalition member's payoff from the current proposal since she dislikes the high payoff of the proposer, but a higher $b$ lowers $H$ 's continuation value. ${ }^{11}$ Unless $a$ is small and $b$ is relatively large, the proposer's pork will be lower than what is predicted by the SSPE without inequity aversion.

When $\alpha^{H}=0.6$ an $L$ still passes $y=50$, but the type of proposal offered by an $H$ proposer depends almost exclusively on $b$. When $b$ is small, an $H$ proposer offers $H_{x y} L_{y} L_{y}$ as in the model without inequity aversion. However, when $b$ is large enough the proposer opts for a universal $H_{x y} H_{y} H_{y} H_{y} L_{y}$ as when $\alpha^{H}=0.3$. The idea is that increasing $b$ lowers the $H$ coalition member's payoff from an $H_{x y} H_{x y} L_{y}$ proposal since she receives a higher payoff than three other players. For both types of proposals the $H$ proposer's pork is decreasing in $a$ but increasing in $b$. As in the case of $\alpha^{H}=0.3$, this generally decreases the proposer's pork unless $b$ is relatively large.

To summarize, in the Weak treatment inequity aversion predicts (i) no differences for an $L$ proposer, (ii) an $H$ proposer offers $H_{x y} H_{y} H_{y} H_{y} L_{y}$ when $\alpha^{H}=0.3$ and also when $\alpha^{H}=0.6$ provided $b$ is high enough, and (iii) an $H$ proposer takes less pork than predicted in each equilibrium proposal so long as $a$ is large enough and/or $b$ is small.

We are interested in whether bargaining proposals are consistent with the SSPE in the VW model, and if not, whether they can be explained by inequity aversion. In particular, (i) Do $L$ proposers in the Strong treatment need to package pork with the public good to pass a proposal? (ii) Do $H$ proposers use the public good as predicted by the SSPE for form coalitions with type $L$ ? (iii) Do $H$ proposers in the Weak treatment continue to use only the public good to form coalitions following the crossover, and if so, do contributions to the public good increase as predicted by the model?

\subsection{Procedures}

This paper tests the three $\left(\alpha^{H}, m\right)$ pairs in Tables 1 and 2 in the laboratory using small groups of subjects with induced preferences over pork and public goods. The experiment was programmed and conducted with the software z-Tree (Fischbacher (2007)). All sessions were conducted at The Ohio State University with participants drawn from the undergraduate student body enrolled in the Economics department subject pool. ${ }^{12}$

Subjects were randomly divided into groups of five players. In each round they were assigned a marginal utility for pork, $\alpha^{H}$ or $\alpha^{L}$, consistent with the treatment under con-

\footnotetext{
${ }^{11}$ As seen previously, since all non-proposing players get the same payoff, $b$ does not affect the payoff from the current proposal.

${ }^{12} \mathrm{http}: / /$ www.trinity.edu/nchristi/doc/Instructions_combined.pdf provides sample instructions.
} 
sideration. While the identities of the other group members were unknown, their values for $\alpha$ were public knowledge. Subjects were then given the task of dividing 50 ECUs using two types of allocations, "allocations to individual voters or allocations to the group as a whole (the group allocation)." 13 Each subject made a proposed allocation on his or her computer between pork and public goods and the computer automatically calculated the dollar payoffs for each subject using the linear payoff function from equation (1) and the subject's value for $\alpha$.

After subjects made their proposals, one proposal in the group was randomly selected to be put to a vote. Players voted to either accept or reject the proposal, and it passed if at least three of five players voted in favor of it. If the proposal was rejected, a new stage commenced whereby the budget was reduced by $20 \%$ (corresponding to $\delta=0.8$ ), and the game was repeated. Subjects were informed as to who voted to accept or reject the proposal chosen for the group immediately following the vote. After each group passed a division of the budget, subjects were randomly assigned to new groups and a new bargaining round began. Subjects' assignment as an $H$ or $L$ changed randomly between rounds, but their types remained constant between stages within a given round.

The data used in the analysis comes only from the choices of experienced subjects, that is subjects participating in their second experimental session. ${ }^{14}$ Each of the experienced sessions began with 14 rounds with a given $\left(\alpha^{H}, m\right)$ pair: $\alpha^{H}=1.5$ and $m=2$ in the Strong treatment and $\alpha^{H}=0.3$ and $m=1$ in the Weak treatment. At the end of the 14 rounds, without prior notification, subjects were told of a modification to the $\left(\alpha^{H}, m\right)$ pair and 10 further bargaining rounds were run. In the Strong treatment $m$ increased to 3 and in the Weak treatment $\alpha^{H}$ increased to 0.6. ${ }^{15}$ We ran 5 sessions of the Strong treatment and 2 sessions of the Weak treatment with 113 and 38 subjects, respectively. ${ }^{16}$ Subjects were paid their payoff in the game for a round randomly drawn from the first set of 14 rounds, and also for a round selected from the second set of 10 rounds. The rounds selected to be paid off on were announced at the end of the session. Average payoffs in experienced

\footnotetext{
${ }^{13}$ There was no mention of either "pork" or "public goods" in the experiment in order to attempt to eliminate any positive or negative associations subjects had with these goods.

${ }^{14}$ Subjects varied somewhat in their type of experience in the Strong treatment. Subjects in early sessions participated in introductory sessions where preferences were heterogeneous $\left(\alpha^{L}<\alpha^{H}\right)$, while later subjects participated in introductory sessions with homogeneous preferences. Despite that difference, the software and instructions were identical for these sessions, and in some cases the dominated strategies and equilibrium outcomes were also quite similar. Nevertheless, we control for different experience in later regression work. Preferences were heterogenous in all introductory sessions for the Weak treatment.

${ }^{15}$ In the Strong treatment with an $L$ majority $(m=3)$, the theory predicts an $L$ proposer can fully fund the public good, but an $H$ proposer is unable to pass a bill without $L$ support. The results replicate findings in Fréchette et al. (2012) and are not reported here, but they are available by request.

${ }^{16}$ The smaller subject pool for the Weak treatment was because the sessions were run at a later date, and it was more difficult to get experienced subjects. The minimum number of subjects across sessions was 18 . When the number of subjects was not a multiple of 5 , some subjects sat out each bargaining round with the guarantee that they would participate in the following round.
} 
Table 3. Aggregate outcomes in accepted proposals: Strong treatment

\begin{tabular}{|c|c|c|c|c|}
\hline Proposer & $\begin{array}{c}\text { Stage 1 } \\
\text { Acceptance } \\
\text { Rate }\end{array}$ & ECUs to Public Good & $\begin{array}{c}\text { Avg \$ Payoff } \\
\text { for } H\end{array}$ & $\begin{array}{c}\text { Avg \$ Payoff } \\
\text { for } L\end{array}$ \\
\hline \hline \multirow{3}{*}{$L$} & $78 \%$ & 43.7 & 10.6 & 8.9 \\
& {$[100 \%]$} & {$[1.19)$} & $(0.29)$ & $(0.19)$ \\
{$[4.2]$} & {$[10.9]$} & $0.4]$ \\
\hline \multirow{3}{*}{$H$} & $85 \%$ & 3.8 & 23.8 & 0.8 \\
& & $(0.74)$ & $(0.23)$ & $(0.15)$ \\
\hline \multirow{4}{*}{ Average } & {$[100 \%]$} & {$[12.4]$} & {$[21.3]$} & {$[2.5]$} \\
& $82 \%$ & 18.9 & 18.8 & 3.9 \\
& & $(1.28)$ & $(0.41)$ & $(0.25)$ \\
\hline
\end{tabular}

Notes: Standard errors of the mean in parentheses. Predicted values in brackets.

Stage 1 proposals only.

sessions were $\$ 21$ and $\$ 18$ in the Strong and Weak treatments, respectively. In addition, subjects were paid a show-up fee and their payout from one round randomly selected from their inexperienced session. ${ }^{17}$

\section{Results}

The results are presented as a series of conclusions with the supporting data directly preceding the conclusion. We begin with the results from the Strong treatment.

\subsection{Strong Treatment}

Table 3 shows the acceptance rate along with contributions to the public good and average payoffs by proposer type. As is standard in the experimental literature on bargaining games, proposals do not always pass in stage 1 as predicted by the theory; the average acceptance rate is slightly higher for $H$ than $L$ proposers, though the difference narrowly misses statistical significance at conventional levels $(p=0.16$, Mann-Whitney test using the group outcome in stage 1 as the unit of observation). Still, only $5 \%$ of proposals extend

\footnotetext{
${ }^{17}$ The show-up fee was $\$ 8$ per session in the Strong treatment for a total of $\$ 16$ across the two sessions. In the Weak treatment the show-up fee was $\$ 20$ for coming to both sessions since by that point it was clear subjects would benefit from the increased experience of an introductory session. Since the findings are presented separately for the two treatments, we do not expect this difference to affect the results.
} 
Table 4. Chosen $L$ proposals: Strong treatment with an $H$ majority

\begin{tabular}{|c|c|c|c|c|}
\hline Proposal & ECUs to Public Good & ECUs to Pork for $H \mathrm{~s}$ & Frequency & Acceptance Rate \\
\hline \hline SSPE allocation $^{a}$ & $\begin{array}{c}44.1 \\
(0.40)\end{array}$ & $\begin{array}{c}5.9 \\
(0.40)\end{array}$ & $22 \%$ & $88 \%$ \\
& 50 & 0 & $62 \%$ & $81 \%$ \\
\hline $\begin{array}{c}\text { Fully-funded } \\
\text { public good }\end{array}$ & $(-)$ & $(-)$ & & \\
\hline Other & 19.3 & 14.5 & $16 \%$ & $58 \%$ \\
& $(3.74)$ & $(3.46)$ & & \\
\hline
\end{tabular}

Notes: Standard errors of the mean in parentheses.

Stage 1 proposals only.

${ }^{a}$ Pork provided to a single $H$ and $y>0$. The predicted amounts are 47.2 to the public good and 2.8 to pork.

past 2 stages. $^{18}$

The table shows that the average payoff for an $L$ is always below that predicted by the $\mathrm{SSPE}$, though the difference is small when $L$ is the proposer. Across all proposals $L$ 's average payoff (i.e., $L$ 's empirical continuation value) is $\$ 3.9$, which is below the SSPE prediction of $\$ 5.3$. $H \mathrm{~s}$, on the other hand, earn higher average payoffs across all proposals than predicted ( $\$ 18.8$ versus $\$ 17.1$ ), driven by the large average payoff when an $H$ is recognized as proposer.

The SSPE predicts that $L$ proposers must append pork to a public goods proposal to achieve bill passage, but this is not borne out by the data. Table 4 characterizes proposals by $L$ players. ${ }^{19}$ SSPE proposals comprise less than one-quarter of all proposals, which almost always pass. Instead, the modal offer by an $L$ proposer is a fully-funded public goods proposal, an offer consistent with the modified SSPE with inequity aversion, and these proposals pass only slightly less frequently. The result is that average contributions to the public good by $L$ proposers are only slightly lower than predicted by the theory as shown in Table 3, and would be higher if not for the handful of 'Other' proposals allocating pork to the proposer.

Why do $H$ s accept a fully-funded proposal and its $\$ 10$ payoff? The payoff an $H$ can expect to receive on average should the current proposal be defeated, her discounted empirical continuation value, is just over $\$ 15$. It is not because the proposal would be accepted anyway; in $40 \%$ of accepted fully-funded public goods proposals the proposal gets 3 votes,

\footnotetext{
${ }^{18}$ The stage 1 acceptance rates are slightly below comparable Baron-Ferejohn experiments with a discount factor of 0.8 (see, for example, Fréchette et al. (2003), Fréchette et al. (2005a), and Agranov and Tergiman (2014)). This is particularly true of $L$ proposers who, as we will see shortly, often attempt to fully fund the public good.

${ }^{19}$ 'Other' allocations generally involve allocations of pork to oneself or the other $L$, a dominated strategy.
} 
which makes each member of the coalition pivotal. Inequity aversion provides one likely explanation: the $\$ 15$ overstates the attractiveness of waiting until the next stage for an $H$ player who is averse to advantageous inequity since that payoff is driven by an $H_{x} H_{x} H_{x}$ coalition with the other $H$ s and leaves the $L$ s with a zero payoff. Furthermore, if an $L$ proposes $L_{y} L_{y} H_{x y}$ and she is not included in the coalition, her payoff is below $\$ 10$ and another $H$ receives a higher payoff. A second possible explanation is that risk aversion might induce an $H$ to accept $\$ 10$, but this would imply that an $H$ proposer could also capitalize on risk averse coalition partners and allocate herself more than in the SSPE, which as we will see below, does not happen.

When $L$ proposers do offer equilibrium $L_{y} L_{y} H_{x y}$ proposals, Table 4 shows that their allocations closely match what is predicted by the theory. While the amount of pork offered to an $H$ is approximately twice as much pork as is predicted by the model, the excess contribution is small, and it leaves the $L$ with $94 \%$ of his predicted payoff. $H$ coalition partners vote against only $7 \%$ of equilibrium type proposals across all rounds. ${ }^{20}$

Conclusion 1. Contrary to the theory, but consistent with other legislative bargaining experiments, proposals do not always pass in stage 1 as predicted. While the SSPE predicts that an L proposer uses pork to pass a heavily funded public goods proposal, proposers opt instead for fully-funded public goods proposals, which are frequently accepted by $H$ players who forego larger expected payoffs in a second stage. This behavior is consistent with the modified SSPE with inequity averse players. When using pork to secure a majority of votes, an $L$ proposer contributes close to the amount predicted by the SSPE.

$76 \%$ of proposals by $H$ players are type $H_{x} H_{x} H_{x}$ minimum-winning coalition proposals. The remainder generally contribute small amounts to the public good in addition to pork to all three $H$ s. The SSPE prediction that $H$ should offer proposals that allocate some funds to the public good and keep the remainder in pork with probability 0.59 is completely rejected by the data (less than $2 \%$ of $H$ proposals are of this type), but the overall decrease in the frequency of these proposals is consistent with inequity aversion. As Table 3 indicates, the result is that there is more pork produced in this region when $H$ s propose than is predicted by the SSPE, and this drives down $L$ 's empirical continuation value. ${ }^{21}$

\footnotetext{
${ }^{20}$ All equilibrium type proposals contain more than the predicted amount of pork.

${ }^{21}$ In theory an $H$ proposer should be able to exploit the lower payoffs for type $L \mathrm{~s}$ that results from the ubiquity of $H_{x} H_{x} H_{x}$ proposals by offering a small contribution to the public good to get their votes. However, it appears that just offering an $L$ her discounted empirical continuation value would not be enough. Looking at all $H$ proposals not of the $H_{x} H_{x} H_{x}$ variety yields only 6 proposals that got both $L$ votes, which a proposer would need with an equilibrium $H_{x y} L_{y} L_{y}$ coalition. Of the 6 proposals, the minimum payoff to both $L$ s was $\$ 8$ (the $L$ 's maximum payoff in the next stage) implying that a proposer would have to allocate 40 ECUs to the public good to pass the proposal. Her payoff in this case would be $\$ 23$, which is far below what she receives by partnering with other $H \mathrm{~s}$, as shown below.
} 
When offering $H_{x} H_{x} H_{x}$ proposals, $H$ proposers receive a larger share of pork than the coalition members, but again as predicted by the model with inequity aversion, they extract less than predicted by the standard SSPE. ${ }^{22}$ An $H$ proposer takes on average 22.2 ECUs (0.27) versus the predicted 31.8 in accepted stage 1 allocations. ${ }^{23}$ This is more than is given to coalition members $(p<0.01$, Wilcoxon signed rank sum test using the payoffs for each individual as an observation). These averages translate to stage 1 payoffs of $\$ 33.75$ for the proposer and $\$ 20.63$ for coalition members, as opposed to $\$ 47.63$ and $\$ 13.68$, respectively, in the SSPE. While the proposer's take is below what is predicted, it is similar to other distributive games in the literature which have consistently shown less proposal power than is predicted by the theory. ${ }^{24}$

One reason for the lack of proposal power concerns the minimum amount $H$ voters are willing to accept, an amount that is increasing in the degree to which one is averse to advantageous and disadvantageous inequity, all else equal. That is because the nonproposing $H$ s receive a lower payoff than the proposer but more than the $L$ s who get a zero payoff. The median amount rejected by an $H$ coalition member in an $H_{x} H_{x} H_{x}$ proposal in stage 1 is 12 ECUs (\$18.00), which is above her discounted empirical continuation value $(\$ 15.20)$, and far exceeds the 9.12 ECUs $(\$ 13.68)$ the model without inequity aversion says she should accept. The modal offer allocates 15 ECUs $(\$ 22.50)$ to each partner, and the proposer keeps the remaining 20 ECUs $(\$ 30.00)$. This proposal (and any proposal that allocates a partner more than 15 ECUs) is always accepted.

An additional factor limiting $H$ 's proposal power is what happens to proposers who propose "unfair" proposals, which can be punished in future stages by providing that player a lower payoff. ${ }^{25}$ This is not a feature of the SSPE, which relies on history independent play, but it might approximate behavior in actual political decision-making environments. The proposals most likely to be deemed unfair are of the $H_{x} H_{x} H_{x}$ variety since they allocate two $L$ s zero payoffs, and they typically allocate the proposer a higher payoff than the coalition members.

To assess the impact from retaliation, we look at all stage 2 proposals made after the defeat of an $H_{x} H_{x} H_{x}$ proposal in stage 1 . We compare the amount of pork received by the

\footnotetext{
${ }^{22}$ As in the case of $L$ proposers, risk aversion among voters would increase proposal power (Harrington (1990)). More generally, the design of the experiment also affects proposer power. Increased proposer power is seen in Agranov and Tergiman (2014) where players can communicate and in Bradfield and Kagel (2015) where subjects bargain in teams.

${ }^{23}$ The average take for the proposer is 25.9 ECUs $(0.97)$ in rejected stage $1 H_{x} H_{x} H_{x}$ proposals.

${ }^{24}$ The average percentage of the budget going to pork for the proposer in accepted stage 1 allocations is $45 \%$ versus the predicted $64 \%$. As a point of comparison, consider that in the homogeneous case in Fréchette et al. (2012) where similar minimum-winning, pork-only coalitions form, the proposer's average take is $41 \%$ versus the predicted equilibrium amount, $68 \%$.

${ }^{25}$ Because subjects are anonymous and switch groups randomly between rounds (but not within stages in a given round), it is impossible to punish players for behavior in previous rounds.
} 
former proposer with the maximum amount given to the other non-proposing $H$ player(s). ${ }^{26}$ The former proposer's average pork allocation is 5.1 ECUs, which is significantly lower than the average maximum allocation to the other non-proposing $H$ players, 6.0 ECUs $(p<0.01$, Wilcoxon signed rank sum test using the payoffs for each individual as an observation). That difference amounts to just over a $\$ 1$ difference in payoff on average. This difference would likely be larger except that $L$ proposers frequently use no pork while passing fully-funded public goods proposals. Moreover, an $H$ proposer wanting to offer $H_{x} H_{x} H_{x}$ needs each $H$ vote to get it passed, and cannot realistically offer one $H$ player a drastically lower payoff. ${ }^{27}$

Conclusion 2. Contrary to the SSPE, $H$ proposers do not mix over $H_{x y} L_{y} L_{y}$ and $H_{x} H_{x} H_{x}$, opting for the latter offer in a vast majority of proposals. This reduces average contributions to the public good along with L's continuation value for the game. $H$ proposers are unable to take advantage to increase their payoffs because of the unequal payoffs $H_{x y} L_{y} L_{y}$ proposals would generate. In $H_{x} H_{x} H_{x}$ offers proposers receive lower payoffs than predicted by the SSPE, partly because the proposer of a rejected offer can be punished in future stages. The prevalence of $H_{x} H_{x} H_{x}$ offers and the lower payoff of the proposer can be explained by the model with inequity aversion.

In order to measure the degree of inequity aversion, Table 5 looks at the determinants of subject voting across all stage 1 proposals. It reports the results of a probit in which the dependent variable takes the value 1 if the player accepts the proposal and 0 otherwise. We regress all players' votes on own payoff, and an indicator for whether the player is an $H$ to account for their higher continuation value for the game. As in the Fehr-Schmidt utility function, the disadvantageous inequity associated with a proposal is the average difference between the payoff of player $i$ and players with a higher payoff, while advantageous inequity is the average difference when $i$ receives a higher payoff. Finally, we include an indicator variable for late rounds to account for learning over the course of the treatment. Standard errors are clustered at the subject level, and votes on own proposals are not included. ${ }^{28}$

Not surprisingly, own payoff is positive and significant at the $1 \%$ level, as is the indicator for an $H$ voter since all else equal, an $H$ voter has a higher empirical continuation value and thus more to hold out for in a future stage. The coefficient on the indicator for late rounds is negative and significant $(p<0.01)$, indicating that voters also learn with experience that they can sometimes do better by holding out for an additional stage. Both of the

\footnotetext{
${ }^{26}$ We exclude proposals where the same proposer is chosen in stage 2 .

${ }^{27}$ There are ten instances in which an $L$ proposer offers an SSPE proposal with pork to one $H$ after a rejected $H_{x} H_{x} H_{x}$ proposal, and not one of them gives pork to the proposer from the last stage. In addition, there are several instances in which $H$ proposers allocate slightly less to last stage's proposer than to the other coalition member.

${ }^{28}$ Including an indicator variable for whether the subject attended introductory sessions with heterogenous preferences has no effect on the coefficients or the levels of significance so it is dropped here.
} 
Table 5. Voting probits for all players

\begin{tabular}{lc}
\hline Own Payoff & 0.25 \\
& $(0.04)^{* * *}$ \\
Indicator for $H$ voter & -1.96 \\
& $(0.20)^{* * *}$ \\
Disadvantageous inequity $^{a}$ & -0.07 \\
& $(0.02)^{* * *}$ \\
Advantageous inequity $^{b}$ & -0.04 \\
& $(0.05)$ \\
Indicator for late rounds $^{c}$ & -0.31 \\
& $(0.11)^{* * *}$ \\
Constant & -0.50 \\
& $(0.40)$ \\
\hline
\end{tabular}

Notes: Stage 1 only. Votes by proposing players are excluded.

Standard errors clustered at the subject level. Standard errors in parentheses.

${ }^{*}$ significant at $10 \% ;{ }^{* *}$ significant at $5 \% ;{ }^{* * *}$ significant at $1 \%$.

${ }^{a}(1 / 4) \sum_{j \neq i} \max \left\{U_{j}-U_{i}, 0\right\}$.

${ }^{b}(1 / 4) \sum_{j \neq i} \max \left\{U_{i}-U_{j}, 0\right\}$.

${ }^{c}$ Indicator function is 1 for rounds 8-14 (0 otherwise).

coefficients on disadvantageous and advantageous inequity are negative, which is consistent with Fehr-Schmidt's characterization of inequity aversion. However, only the coefficient on disadvantageous inequity is significant $(p<0.01)$ suggesting players are more averse to receiving lower payoffs than other players. ${ }^{29}$ The magnitude of the disadvantageous inequity coefficient is over one-quarter the magnitude of the own payoff coefficient so that while own payoff is still a voter's dominant concern, disadvantageous inequity is a significant factor in the voting decision.

We can use the results of the probit to get a better understanding of the absence of equilibrium $H_{x y} L_{y} L_{y}$ offers. Even assuming the offer is made in early rounds when voters are less likely to hold out for high payoffs, the predicted probability that an SSPE offer (29 ECUs to the proposer in pork and 21 ECUs to the public good) gets both $L$ votes is only $16 \%$, which leaves the proposer with an expected payoff of $\$ 20.36 .^{30}$ The predicted payoff maximizing $H_{x y} L_{y} L_{y}$ proposal allocates 19 to the proposer in pork and 31 to the public good for an expected payoff to the proposer of $\$ 22.09$. Contrast this to the proposer's

\footnotetext{
${ }^{29}$ The $p$-value for the coefficient on advantageous inequity is 0.36 . It is likely that collinearity between this term and own payoff is masking some of the effect of inequity aversion on voting decisions. This is because when a player's own payoff is high, it is likely to result in high advantageous inequity, and vice versa.

${ }^{30}$ The payoff if the proposal is rejected is the proposer's discounted empirical continuation value.
} 
payoff in the modal $H_{x} H_{x} H_{x}$ proposal that allocates 20 ECUs to the proposer in pork and 15 in pork to each coalition member, which passes $100 \%$ of the time in the experiment and guarantees the proposer $\$ 30$. It is no wonder then that $H$ proposers deviate from the SSPE prediction.

Conclusion 3. Increased disadvantageous and advantageous inequity in a proposal reduce the probability of acceptance in the experiment, though only the amount of disadvantageous inequity is statistically significant in the voting probit regression. While inequity aversion makes it more likely an $L$ proposer can pass $y=50$, it also induces $H$ proposers to allocate the budget entirely to pork instead of attempting to win $L$ votes with the public good. The net effect is to limit contributions to the public good in the Strong treatment.

\subsection{Weak Treatment}

In over $89 \%$ of proposals in the Weak preference treatment with four $H$ s and one $L, L$ proposers contribute everything to the public good for both $\alpha^{H}=0.3$ and $\alpha^{H}=0.6$ as the SSPE predicts. ${ }^{31}$ All players then receive payoffs of $\$ 10$. Almost no $H$ votes against this type of proposal, and they are always passed as predicted by the SSPE with and without inequity aversion.

When $\alpha^{H}=0.3 H$ proposers form universal $H_{x y} H_{y} H_{y} H_{y} L_{y}$ coalitions $77 \%$ of the time as predicted with much of the remainder allocating the entire budget to the public good. The pass rate of the equilibrium offers is $90 \%$. As occurred previously in the Strong treatment, the $H$ proposer's take in pork is significantly less than predicted by the SSPE, which is consistent with the modified SSPE with inequity aversion. The theoretical share of pork for a proposer is 16.7 ECUs while in the experiment the average amount in accepted stage 1 allocations is 6.2 ECUs (0.38). ${ }^{32}$ While the share of pork for the proposer is far below the predicted amount, the difference in average payoff to the proposer is small. The predicted payoff to the proposer in the model is $\$ 11.67$, while it is $\$ 10.62$ in accepted allocations.

$H$ proposals deviate from the SSPE predictions when $\alpha^{H}=0.6$. Instead of an equilibrium type $H_{x y} H_{x y} L_{y}$ proposal which funds the public good and gives pork to the one other $H$ in addition to the proposer, $H$ proposers offer universal $H_{x y} H_{y} H_{y} H_{y} L_{y}$ coalitions as with $\alpha^{H}=0.3$ in $65 \%$ of chosen proposals, which have a pass rate of $81 \%$. Note that these proposals are consistent with equilibrium in the model with inequity aversion provided players care enough about advantageous inequity. The remainder of proposals are of the $H_{x} H_{x} H_{x}$ type or offer some combination of pork to the proposer and two other $H \mathrm{~s}$, and a positive

\footnotetext{
${ }^{31}$ The remainder of proposals generally give small amounts of pork to the proposer.

${ }^{32}$ The proposer's share is nearly equivalent to the share reported in Fréchette et al. (2012) for similar types of proposals. 6.2 ECUs is $12.4 \%$ of the budget, and in their paper proposers kept between $10.1 \%$ and $14.3 \%$ of the budget in pork for values of $\alpha$ that roughly correspond to $\alpha^{H}=0.3$ in this paper.
} 
amount to the public good. $H$ proposers receive lower payoffs than predicted. For those proposers offering $H_{x y} H_{y} H_{y} H_{y} L_{y}$ proposals the average share in pork for the proposer is 6.7 ECUs (0.37) in accepted stage 1 proposals, and the proposer's average payoff is $\$ 12.69$, which is well below the predicted $\$ 18.44$.

Conclusion 4. As the theory predicts, no pork is necessary for $L$ proposers to pass fullyfunded public goods proposals when the $H s^{\prime}$ preference for pork is weak, even when the majority of players are type $H$. For both values of $\alpha^{H}, H$ proposers frequently contribute to the public good and allocate the remainder of the budget to themselves in pork. This is in accordance with the theory when $\alpha^{H}=0.3$. It contradicts it when $\alpha^{H}=0.6$, but it is consistent with the model with inequity aversion when players are sufficiently averse to advantageous inequity.

No matter what type of proposal $H$ proposers offer, the theory with and without inequity aversion predicts that the value of the game for $H \mathrm{~s}$ increases by increasing $\alpha^{H}$, so that proposers must offer $H$ coalition members high payouts when $\alpha^{H}=0.6$. When $H$ proposers make universal $H_{x y} H_{y} H_{y} H_{y} L_{y}$ proposals and attempt to win $H$ votes with the public good, this means increasing $H$ 's marginal utility for pork actually increases the public good allocation necessary to win her vote. Fréchette et al. (2012) examine this prediction and find the opposite to be true: the share allocated to the public good falls as the players' relative preference for pork increases.

The fact that the majority of proposals in both treatments are universal $H_{x y} H_{y} H_{y} H_{y} L_{y}$ offers provides a natural framework to test the model's prediction. ${ }^{33}$ The model predicts that when $\alpha^{H}=0.3$, the necessary share allocated to the public good to win an $H$ player's vote is $y=33$, which rises to 36 when the marginal utility for pork doubles to $\alpha^{H}=$ 0.6. While this is not an equilibrium proposal in the SSPE without inequity aversion, the amounts of pork and public good are based on the $H$ players' equilibrium continuation value for the game. The theoretical payoffs to the coalition members are then $\$ 6.67$ and $\$ 7.11$, respectively.

Looking at all accepted stage $1 H_{x y} H_{y} H_{y} H_{y} L_{y}$ proposals across treatments, the amount contributed to the public good falls slightly from 43.8 ECUs (0.38) when $\alpha^{H}=0.3$ to 43.3 ECUs (0.37) when $\alpha^{H}=0.6$, though the difference is not statistically significant ( $p=0.37$, Mann-Whitney test using each proposal as an observation). ${ }^{34}$ Rejected stage $1 H_{x y} H_{y} H_{y} H_{y} L_{y}$ offers tell a similar story. Across all rounds there is again no significant difference in the amount contributed to the public good, as the amounts are 39.0 (0.82) and

\footnotetext{
${ }^{33}$ By focusing on $H$ votes on just these proposals we eliminate the need to control for players' differential responses to other types of proposals.

${ }^{34}$ The median contribution also falls slightly from 45 to 44 ECUs. In late rounds after players have even more experience with the bargaining game, the amount contributed to the public good is identical between treatments.
} 
Table 6. Probit of $H$ votes on $H_{x y} H_{y} H_{y} H_{y} L_{y}$ proposals

\begin{tabular}{cc}
\hline ECUs to Public Good & 0.16 \\
& $(0.04)^{* * *}$ \\
Indicator for $\alpha^{H}=0.6$ Treatment & -8.25 \\
& $(3.24)^{* *}$ \\
Indicator for $\alpha^{H}=0.6$ Treatment $*$ & 0.20 \\
ECUs to Public Good & $(0.08)^{* *}$ \\
Constant & -6.42 \\
& $(1.89)^{* * *}$ \\
\hline
\end{tabular}

Notes: Stage 1 only. Votes by proposing players are excluded. Standard errors in parentheses. Standard errors clustered at the subject level.

${ }^{*}$ significant at $10 \% ;{ }^{* *}$ significant at $5 \% ;{ }^{* * *}$ significant at $1 \%$.

39.1 (0.79) for $\alpha^{H}=0.3$ and 0.6, respectively ( $p=0.68$, Mann-Whitney test using each proposal as an observation). While this suggests no difference in public good contributions when $\alpha^{H}$ rises, it is still possible that $H$ voters are holding out for higher contributions as predicted by the model. This is because an $H$ proposer only needs one or two $H$ votes out of three (depending on whether the $L$ voter accepts the proposal) so that if a few $H$ voters do not change their behavior, it is possible that average accepted contributions remain unchanged.

To investigate changes in individual voting we run a probit on voting decisions across treatments over stage $1 H_{x y} H_{y} H_{y} H_{y} L_{y}$ proposals. Table 6 reports the results where the explanatory variables are the contribution to the public good, an indicator which is 1 when $\alpha^{H}=0.6$ and 0 otherwise, and an interaction term between the indicator and the contribution to the public good. ${ }^{35}$ As expected, the regressions show that the coefficient on the contribution to the public good is positive and significant. Despite what is implied by the average accepted contributions to the public good, the probits show that $H$ 's voting behavior is consistent with the theoretical model. That is, the coefficient on the indicator for the $\alpha^{H}=0.6$ treatment is negative and significant, while the interaction term is positive and significant. This suggests that there is a fixed negative effect on acceptance probability when $\alpha^{H}=0.6$, but the effect dissipates as the contribution to the public good rises. This

\footnotetext{
${ }^{35}$ Note that there is no need to control for inequity aversion in the regression. This is because all nonproposing players receive the same payoff so there is no advantageous inequity to control for. Furthermore, the non-proposers' payoff is perfectly correlated with the proposer's payoff since whatever is not contributed to the public good is kept in pork for the proposer. This means any aversion to disadvantageous inequity is expressed in the coefficient on the public good contribution. We did run additional regressions including an indicator for late rounds, but the coefficient on this indicator is insignificant and it does not affect the coefficients on the other variables, so we drop it here.
} 
Figure 1. Average number of yes votes on $H_{x y} H_{y} H_{y} H_{y} L_{y}$ proposals

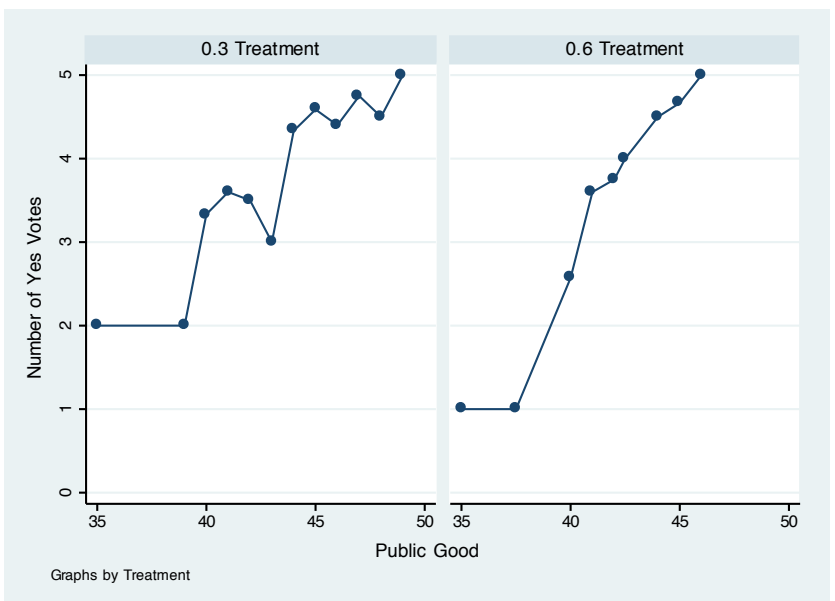

Notes: Stage 1 proposals only.

is entirely as predicted by the theory as there should be no difference in the propensity to accept a proposal once the public goods contribution gets sufficiently large $(y \geq 36$ according to the theory).

One potential concern with the voting probit is that $H$ voters are not always pivotal in the voting decision, which makes interpretation of their voting behavior problematic. To address this concern we first look at the average number of yes votes for each level of public good contribution in $H_{x y} H_{y} H_{y} H_{y} L_{y}$ proposals to determine when an $H$ voter is likely to be pivotal. This is shown in Figure 1, which plots the relationship between total votes and public good contributions by treatment. Two things stand out in figure: first, an $H$ is very likely to be pivotal for proposals at 40 ECUs and below. The average number of votes for $y=40$ is just over 3 when $\alpha^{H}=0.3$ and under 3 for $\alpha^{H}=0.6$. Second, in both treatments, once the proposal reaches 45 ECUs the voter is unlikely to be pivotal as the proposal is likely to pass with or without her vote. Re-running the same probit regression on $H_{x y} H_{y} H_{y} H_{y} L_{y}$ proposals with $y \leq 40$ and $y<45$ gives essentially the same results. That is, in both cases, the indicator for the $\alpha^{H}=0.6$ treatment is negative and significant, and the interaction term of the indicator with own payoff is positive and significant. ${ }^{36}$ This suggests that when the proposal is more likely to hinge on their vote, $H$ players are still holding out for higher payoffs when $\alpha^{H}=0.6$.

Given that the average accepted contributions to the public good in $H_{x y} H_{y} H_{y} H_{y} L_{y}$

\footnotetext{
${ }^{36}$ For $y \leq 40$ both coefficients are significant at the $1 \%$ level, while they are significant at the $10 \%$ level for $y<45$.
} 
proposals do not change, it is clear that not all $H$ players are responding to the increase in $\alpha^{H}$ as the model predicts. One explanation is that some players use the discounted payoff from a fully-funded public goods proposal as a reference point in determining a minimum threshold of acceptance. This involves a proposal of 40 ECUs to the public good for a payoff of $\$ 8$, and this payoff does not change as $\alpha^{H}$ changes. There are $99 H_{x y} H_{y} H_{y} H_{y} L_{y}$ proposals put to a vote across both values of $\alpha^{H}$, only 4 offer less than 40 ECUs to the public good, and almost no non-proposing $H$ votes in favor of the proposal. The most common contributions to the public good for each value of $\alpha^{H}$ are 40 ECUs (25 proposals) and 45 ECUs (23 proposals), with most of the remainder in between these two amounts. That means for both values of $\alpha^{H}$ bargaining essentially starts at 40 ECUs to the public good as if proposers expect that offering anything less is likely to fail. ${ }^{37}$ If some players use the discounted payoff from a fully-funded public goods proposal as a minimum threshold, then increasing the marginal utility of pork would have no effect on their voting decisions. And if enough players use that reference point then we would expect no change in accepted public good contributions even if some voters hold out for higher contributions.

Why do the findings differ from those in Fréchette et al.? While much of the bargaining process is similar between Fréchette et al. and this paper, there is an important difference: the marginal return on the public good does not change in the Weak treatment, while in Fréchette et al. the return declines as the marginal utility for pork increases. ${ }^{38}$ Both papers use $\delta=0.8$ and a budget of 50 ECUs so that to give players the payoff in a discounted fully funded public goods proposal, the proposer must allocate 40 ECUs to the public good in stage 1. Suppose players use that proposal as a reference point as this experiment suggests they do. When the return on an ECU given to the public good declines as the marginal utility for pork increases, the opportunity cost to the voter of accepting a smaller public goods contribution relative to the reference point also declines. This provides a possible explanation for why there is a lower threshold of acceptance in Fréchette et al. but no change in this paper.

Conclusion 5. When $H$ proposers use only the public good to win coalition votes, average accepted contributions to the public good do not decrease when $\alpha^{H}$ increases as previous work has shown. But they also do not rise as predicted by the theory. The probits show $H$ voters do hold out for higher contributions on average when $\alpha^{H}$ increases, but the willingness of

\footnotetext{
${ }^{37}$ Given that even 40 ECUs gets only $55 \%$ of non-proposing $H$ votes for $\alpha^{H}=0.3$ and $38 \%$ of those votes for $\alpha^{H}=0.6$ suggests voters would likely respond unfavorably to $y<40$.

${ }^{38}$ In that paper they use an early version of the VW model which explicitly relates preferences for pork and the public good. The marginal utility from the public good is $(1-\alpha) q$ where $\alpha$ is the marginal utility from pork for all players. They fix $q=0.7$ and consider three values of $\alpha$ where the equilibrium proposal is for the proposer to win votes using the public good (and keep the remainder in pork), 0.45, 0.55, and 0.65. The marginal utility from the public good is $0.39,0.32$, and 0.25 for $\alpha$ equal to $0.45,0.55$, and 0.65 , respectively.
} 
some voters to still accept lower public good contributions leaves average levels unchanged. This can be explained by a reference point effect in which some subjects use the discounted payoff from a fully-funded public goods offer in determining how to vote.

\section{Discussion}

This paper uses experiments to investigate the predictions of the Volden-Wiseman model in which legislators with heterogeneous preferences bargain over pork and public goods contributions from a fixed budget. We extend the literature in two ways. First, given our experimental design, we solve for the stationary subgame perfect equilibrium in the VW model when players have Fehr-Schmidt preferences and investigate the predictions using laboratory experiments. Second, we examine the main comparative statics prediction of the VW model, which is that increasing the preference for pork can increase public goods contributions.

The results show that fairness concerns do not necessarily lead to greater public goods contributions. The set-up in this experiment is very different from typical experiments on voluntary contribution mechanisms, but one of the stylized facts in that literature is that contributions to the public good far surpass what is rational in the classical sense, at least partly because subjects have social preferences. ${ }^{39}$ Average contributions to the public good fall in the Strong treatment with inequity aversion despite the fact that $L$ proposers are able to pass fully-funded public goods proposals more frequently with inequity averse players. This is because with $H$ proposers $L$ players are unwilling to accept the small public goods allocations predicted by the theory, which leave them with much lower payoffs than the proposer. As we show both theoretically and empirically, $H$ proposers respond by allocating only pork and nothing to the public good.

The results from the experiment are consistent with the SSPE predictions when players are inequity averse, unlike the results in legislative bargaining experiments with only private goods (see the predictions already discussed in Montero (2007)). There is a large experimental literature on Baron-Ferejohn bargaining games, and one of the consistent findings is that proposers receive lower - not higher-payoffs than predicted by the model. ${ }^{40}$ In contrast to Montero's paper, the theoretical effect of including inequity aversion when bargaining over pork and a public good is often to reduce payoff inequity by lowering the payoff of the proposer. ${ }^{41}$ We show that in both treatments for our chosen parameters it is always the case

\footnotetext{
${ }^{39}$ See Ledyard (1995).

${ }^{40}$ See, for example, Fréchette et al. (2005a) and Fréchette et al. (2005b).

${ }^{41}$ Montero's paper shows that the proposer's share of the pie is increasing in $a$ and $b$ provided the discount factor is high enough, thereby increasing payoff inequity. Inequity aversion also strengthens the position of an $L$ proposer in the VW model who can now pass $y=50$ even in the Strong treatment, but in this case inequity in payoffs is falling as the proposer's power rises.
} 
that increased distaste for disadvantageous inequity (i.e., increasing the parameter $a$ ) lowers $H$ proposer's power. All else constant, increasing distaste for advantageous inequity (i.e., increasing the parameter $b$ ) also decreases the proposer's pork when she allocates pork to coalition members but increases it when she uses the public good, potentially contributing to greater inequity. However, given our assumption that $a \geq b$-an assumption reinforced by the probit results - the effects of increasing $a$ quickly dominate any increased proposer power from increased $b$ so that proposer power only increases relative to the standard SSPE when $a$ is small and $b$ is relatively large.

What accounts for the different results surrounding payoff inequity and proposer power in the Montero paper? In that paper coalition members are afraid of being left out of a winning coalition in a future stage. This is because proposers always form minimumwinning coalitions, which leave players outside the coalition with no pork and a zero payoff. But this rarely happens in the VW model, as there is usually little chance of receiving a zero payoff in a future stage since the public good is often funded with high probability in equilibrium. The presence of a public good mitigates some of the potential inequity in future stages, and discourages players from accepting low payoffs.

One of the limitations of the theoretical analysis is that it only solves for the equilibrium in the VW model for the parameter configurations used in the experiment. This is done because the model quickly becomes intractable with added complexity. However, the coalitions that form in the stationary subgame perfect equilibria for the parameter choices in the experiment are representative of the coalitions that form for other configurations. ${ }^{42}$ This suggests the results related to $a$ and $b$ are likely to hold more generally.

Fréchette et al. (2012) find lower contributions to the public good when the marginal utility for pork increases and proposers use the public good to win coalition votes, whereas we find no change in the amount given. Both results run contrary to the theory which predicts that contributions rise as the marginal utility for pork increases. An important difference between the two papers is that in Fréchette et al. the return on the public good declines as the marginal utility for pork increases while in this paper the return is constant, meaning that if players use the payoff from a fully-funded public goods proposal as a reference point in determining what to accept, players may be willing to settle for less in their study. Fréchette et al. point out that the lower return on the public good may drive their findings, and the results in this paper provide some support for that assertion. However, the fact that some subjects in this experiment do not change their voting behavior

\footnotetext{
${ }^{42}$ That is to say, in every equilibrium coalition of the model an $L$ proposer either fully funds the public good or contributes pork to enough $H$ s to form a minimum-winning coalition. An $H$ proposer either (i) forms a minimum-winning coalition using only pork, (ii) forms a mixed minimum-winning coalition of $L \mathrm{~s}$ and $H$ s using pork and public good, or (iii) uses only the public good to achieve bill passage and keeps the remainder of the budget in pork. All of these coalitions are represented in the equilibria of the Strong and Weak treatments.
} 
masks the fact that others respond in the way predicted by the theory. The probit results in the Weak treatment show that on average $H$ s hold out for higher contributions to the public good when the preference for pork rises, but this does not increase aggregate accepted public goods contributions because an $H$ proposer typically needs only one out of three nonproposing $H$ voters to accept the same public goods contribution as before the increase in marginal utility.

\section{References}

Agranov, M., Tergiman, C., 2014. "Communication in multilateral bargaining". Journal of Public Economics 118, 75-85.

Baron, D., Ferejohn, J., 1989. "Bargaining in legislatures". American Political Science Review 83, 1181-1206.

Battaglini, M., Nunnari, S., Palfrey, T.R., 2012. "Legislative bargaining and the dynamics of public investment". American Political Science Review 106, 407-429.

Battaglini, M., Nunnari, S., Palfrey, T.R., 2014. "Dynamic free riding with irreversible investments". American Economic Review 104, 2858-2871.

Bradfield, A.J., Kagel, J.H., 2015. "Legislative bargaining with teams". Mimeo.

Christiansen, N., 2013. "Strategic delegation in a legislative bargaining model with pork and public goods". Journal of Public Economics 97, 217-229.

Christiansen, N., Georganas, S., Kagel, J.H., 2014. "Coalition formation in a legislative voting game". American Economic Journal: Microeconomics 6, 182-204.

Christiansen, N., Kagel, J.H., 2015. "Reference point effects in legislative bargaining: Experimental evidence". Mimeo.

Diermeier, D., Morton, R., 2005. "Experiments in majoritarian bargaining", in: AustenSmith, D., Duggan, J. (Eds.), Social Choice and Strategic Decisions: Essays in the Honor of Jeffrey S. Banks. Springer, Berlin.

Fehr, E., Schmidt, K.M., 1999. "A theory of fairness, competition, and cooperation". Quarterly Journal of Economics 114, 817-868.

Fischbacher, U., 2007. "z-tree: Zurich toolbox for ready-made economic experiments". Experimental Economics 10, 171-178. 
Fréchette, G.R., Kagel, J.H., Lehrer, S.F., 2003. "Bargaining in legislatures: An experimental investigation of open versus closed amendment rules". American Political Science Review 97, 221-232.

Fréchette, G.R., Kagel, J.H., Morelli, M., 2005a. "Gamson's law versus non-cooperative bargaining theory". Games and Economic Behavior 51, 365-390.

Fréchette, G.R., Kagel, J.H., Morelli, M., 2005b. "Nominal bargaining power, selection protocol, and discounting in legislative bargaining". Journal of Public Economics 89, $1497-1517$.

Fréchette, G.R., Kagel, J.H., Morelli, M., 2012. "Pork versus public goods: An experimental study of public good provision within a legislative bargaining framework". Economic Theory 49, 779-800.

Harrington, J.E., 1990. "The role of risk preferences in bargaining when acceptance of a proposal requires less than unanimous approval". Journal of Risk and Uncertainty 3, $135-154$.

Jackson, M.O., Moselle, B., 2002. "Coalition and party formation in a legislative voting game". Journal of Economic Theory 103, 49-87.

Ledyard, J.O., 1995. "Public goods", in: Kagel, J.H., Roth, A.E. (Eds.), Handbook of Experimental Economics. Princeton University Press, Princeton.

Lizerri, A., Persico, N., 2001. "The provision of public goods under alternative electoral incentives". American Economic Review 91, 225-239.

McKelvey, R.D., 1991. "An experimental test of a stochastic game model of committee bargaining”, in: Palfrey, T.R. (Ed.), Laboratory Research in Political Economy. University of Michigan Press, Ann Arbor.

Montero, M., 2007. "Inequity aversion may increase inequity". The Economic Journal 117, C192-C204.

Tergiman, C., 2015. "Institution design and public good provision: an experimental study of the vote of confidence procedure". Experimental Economics .

Volden, C., Wiseman, A., 2007. "Bargaining in legislatures over particularistic and collective goods". American Political Science Review 101, 79-92.

Volden, C., Wiseman, A.E., 2008. "Erratum to bargaining in legislatures over particularistic and collective goods". American Political Science Review 102, 385-386. 


\section{A Fehr-Schmidt Preferences}

In what follows we characterize the SSPE for the parameter values in the Strong and Weak treatments given the preferences with inequity aversion in equation (2) instead of re-solving the VW model more generally. ${ }^{43}$ Unless otherwise noted, we consider $0 \leq a \leq 5$. A player with $a>0$ is willing to reduce her payoff by 1 if it means reducing the utility of another player with a higher payoff by $(1+a) / a$. So a player with $a$ close to 0 requires a large reduction in the other player's payoff to reduce her own payoff by 1 , but a player with $a=5$ is extremely averse to disadvantageous and requires only 1.2. We also assume $a \geq b$ and $0 \leq b<\left(\alpha^{H}-q\right) / \alpha^{H}=0.87$. If $b$ exceeds this "advantageous inequality" threshold, an $H$ prefers to fully fund the public good rather than allocate pork.

One thing is worth noting about the $b$ parameter in the model with inequity aversion, which will provide some intuition into the modified equilibrium. The proposer always offers the marginal coalition member exactly her continuation value for the game. Suppose that player is type $H$. If her payoff is not greater than the payoff of any other player, then she incurs no advantageous inequality, and the only role of $b$ is to reduce her expected utility of the game should the group continue to a future stage and she should receive a higher payoff than another player. In this case, a higher $b$ will always lower $H$ 's continuation value and allow the proposer to achieve a higher payoff.

\section{A.1 Strong Treatment}

Figure 2. SSPE in the Strong Treatment with Inequity Aversion

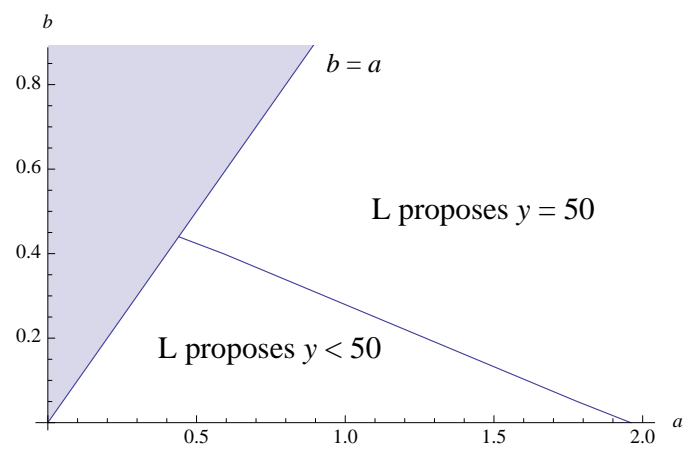

Notes: For $\alpha^{H}=1.5, q=0.2, m=2$, and $\delta=0.8$. Figure assumes $a \geq b$ and $b<0.87$. $H$ proposer always mixes over $H_{x} H_{x} H_{x}$ and $H_{x y} L_{y} L_{y}$.

Figure 2 provides a general characterization of the equilibrium in the Strong treatment

\footnotetext{
${ }^{43}$ All calculations are available by request.
} 
for the chosen experimental parameter values. If $a$ and $b$ are both small enough, the SSPE has the same flavor as in the VW model. That is, an $L$ proposer offers $L_{y} L_{y} H_{x y}$ and an $\mathrm{H}$ proposer mixes over $H_{x} H_{x} H_{x}$ and $H_{x y} L_{y} L_{y}$. However, as $a$ and/or $b$ gets larger an $L$ can propose and pass $y=50$. This is because a large $a$ decreases $H$ 's continuation value to the point that she will accept a fully-funded public goods proposal: there is a $2 / 5$ chance another $H$ will be chosen and in this case the large payoff discrepancy vis-á-vis the proposer significantly lowers her utility. ${ }^{44}$

Table 7 provides the equilibrium budget allocations as a function of $a$ and $b$. As just noted, panel (i) shows that as $a$ and $b$ increase an $L$ proposer's contribution to the public good approaches 50. In panel (ii) the probability that an $H$ proposer allocates only pork in an $H_{x} H_{x} H_{x}$ offer increases with $b$. It increases with $a$ when $L$ proposers are offering $y<50$ in equilibrium and decreases otherwise. Importantly, for all values of $a$ and $b$ considered here, the probability $H$ allocates only pork is higher than what is predicted by the SSPE without inequity aversion. Panels (iii) and (iv) consider the $H$ proposer's share of pork in $H_{x} H_{x} H_{x}$ and $H_{x y} L_{y} L_{y}$ proposals, respectively. The proposer's share declines with $a$ in both cases, but when offering $H_{x} H_{x} H_{x}$ proposals increasing $b$ serves to further decrease the proposer's payoff.

The important thing to take away from Table 7 is that with inequity averse preferences, it is more likely that $L$ can pass $y=50$ in equilibrium, and the probability of an $H_{x} H_{x} H_{x}$ proposal increases, along with a decrease in the amount the proposer is able to keep in pork relative to the SSPE without inequity aversion.

\section{A.2 Weak Treatment}

When $\alpha^{H}=0.3$ the type of proposals offered are unchanged in equilibrium for $b<0.87$ and $0 \leq a \leq 5$. An $L$ proposer continues to propose and pass $y=50$, while an $H$ proposer contributes enough to the public good to get unanimous approval while keeping the rest for herself in pork. The type of proposals offered in equilibrium when $\alpha^{H}=0.6$ are also unchanged so long as $b$ is low. Figure 3 plots an $H$ proposer's equilibrium proposal type as a function of $a$ and $b$, and shows the type of proposal chosen is almost completely independent of $a$. For low $b$ an $H$ proposer offers $H_{x y} H_{x y} L$ as in the model without inequity aversion, but for high enough $b$ she switches to $H_{x y} H_{y} H_{y} H_{y} L_{y}$. The intuition is that, all else equal, a high $b$ reduces the payoff of the $H$ coalition member in an $H_{x y} H_{x y} L_{y}$ proposal, and the proposer must respond by increasing her payoff. At some point it becomes more attractive to switch to a universal proposal where all non-proposing players incur no advantageous inequity.

\footnotetext{
${ }^{44}$ The result is analogous to the finding in Montero (2007), in which a proposer in the classic BaronFerejohn game does better when individuals are inequity averse.
} 
Table 7. SSPE in Strong Treatment with Inequity Aversion

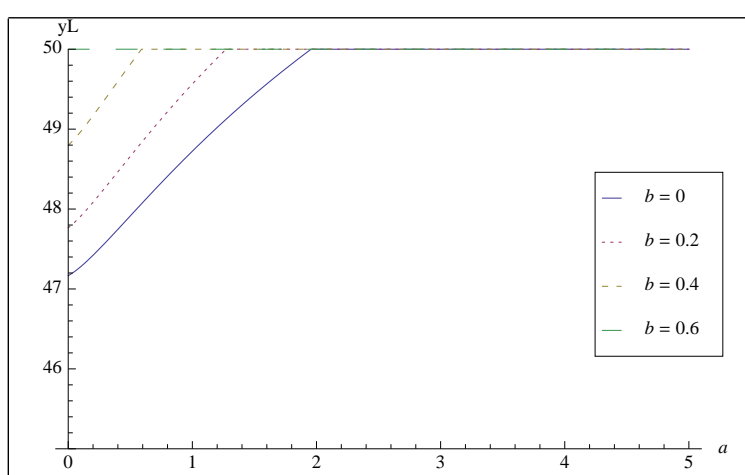

(i) $L$ Proposer: Contribution to public good $(y)$

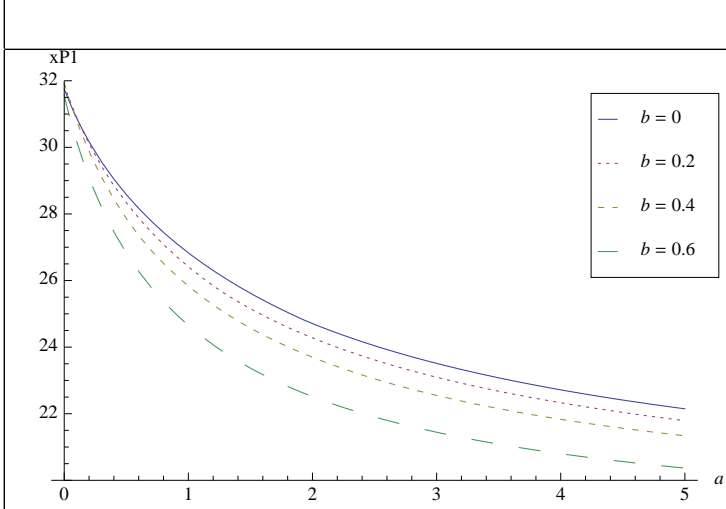

(iii) $H$ Proposer: proposer's pork $(x)$ in $H_{x} H_{x} H_{x}$ proposal

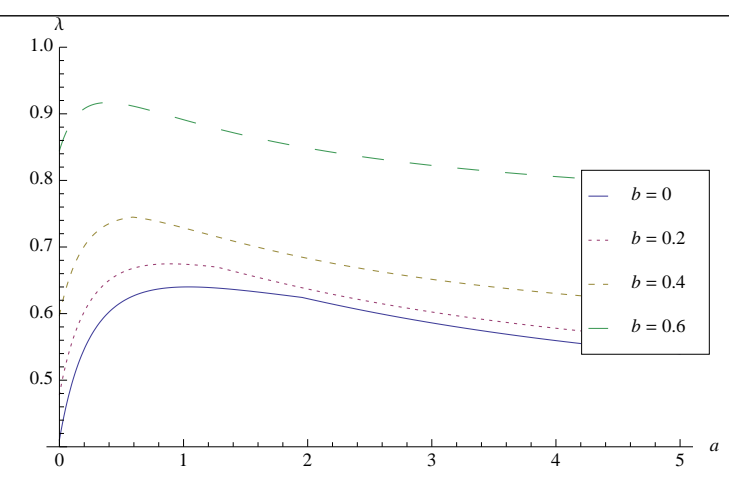

(ii) $H$ Proposer: probability $(\lambda)$ of $H_{x} H_{x} H_{x}$ proposal

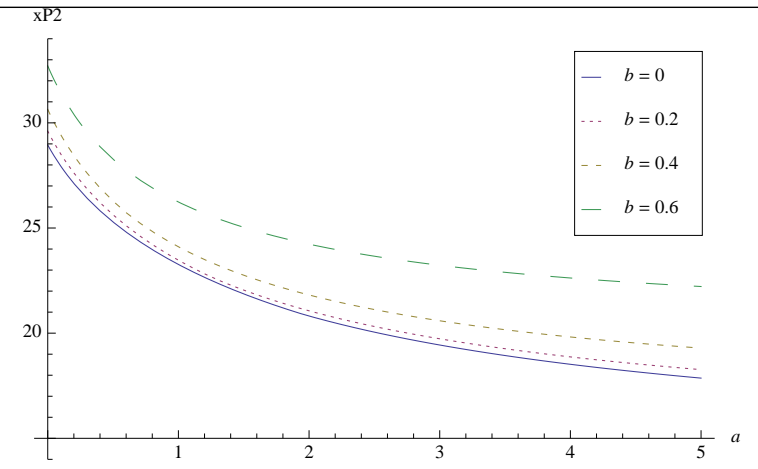

(iv) $H$ Proposer: proposer's pork $(x)$ in $H_{x y} L_{y} L_{y}$ proposal

Notes: SSPE predictions in VW model are where $a, b=0$.

Table 8 graphs pork to the proposer across both values of $\alpha^{H}$ in the Weak treatment. Panels (i) and (ii) show the $H$ proposer's pork when making an $H_{x y} H_{y} H_{y} H_{y} L_{y}$ proposal when $\alpha^{H}=0.3$ and 0.6 , respectively. In both cases higher $b$ increases the proposer's share, while higher $a$ decreases it. The idea is that increasing $a$ pushes down the payoff for a non-proposing $H$ from the current $H_{x y} H_{y} H_{y} H_{y} L_{y}$ offer faster than the continuation value, and the proposer must respond by increasing $y$. As far as $b$ goes, increasing it lowers $H$ 's continuation value since the payoff as proposer in a future stage declines, and the proposer takes advantage by taking more pork. Comparing panel (i) to (ii) also shows that increasing $\alpha^{H}$, while holding $a$ and $b$ constant, decreases the proposer's pork (and increases the contribution to the public good). ${ }^{45}$ Panels (iii) and (iv) show the division of pork in

\footnotetext{
${ }^{45}$ The easiest way to see this is to compare the lines for $b=0.6$ across both panels. The line moves down in panel (ii) relative to panel (i).
} 
Figure 3. SSPE in the Weak Treatment $\left(\alpha^{H}=0.6\right)$ with Inequity Aversion

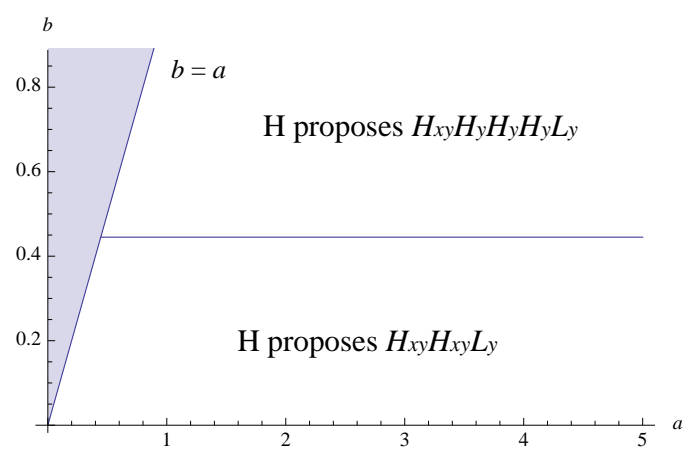

Notes: For $\alpha^{H}=0.6, q=0.2, m=1$, and $\delta=0.8$. Figure assumes $a \geq b$ and $b<0.87$. $L$ proposer always proposes $y=50$.

an $H_{x y} H_{x y} L_{y}$ proposal. While $b$ has almost no effect on the equilibrium contributions, increasing $a$ lowers pork to both players as more is contributed to the public good. Here a higher $a$ reduces the attractiveness of the proposal to both the $H$ and $L$ coalition members, and the proposer responds with higher (and more equitable) payoffs. 
Table 8. SSPE in Weak Treatment with Inequity Aversion

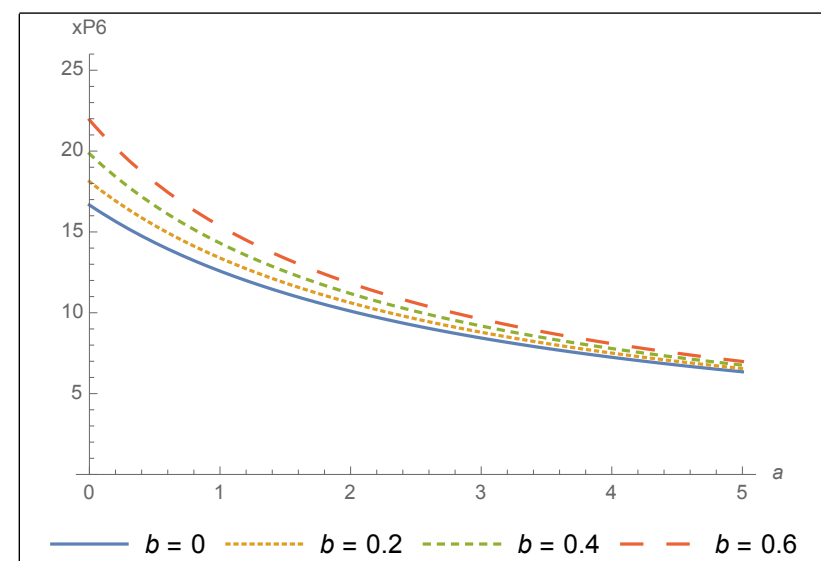

(i) $H$ Proposer: proposer's pork in \begin{tabular}{|l|l} 
& $H_{x y} H_{y} H_{y} H_{y} L_{y}$ proposal when $\alpha^{H}=0.3$ \\
\hline xP5 &
\end{tabular}

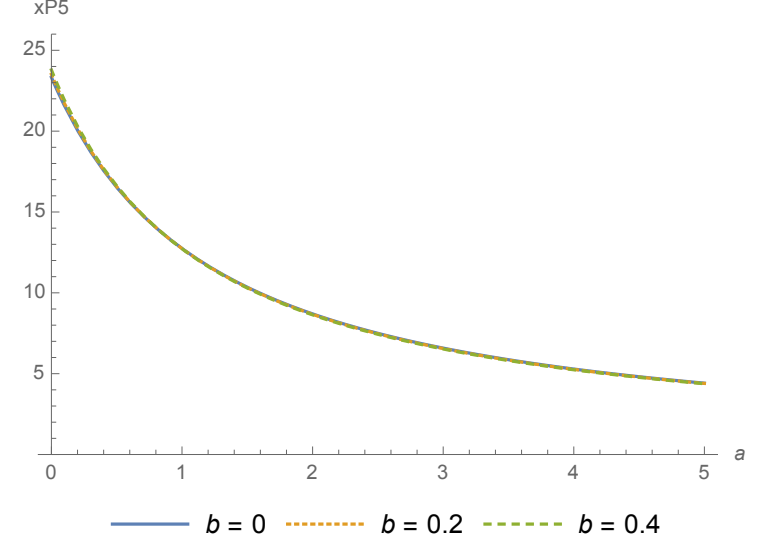

(iii) $H$ Proposer: proposer's pork in $H_{x y} H_{x y} L_{y}$ proposal when $\alpha^{H}=0.6$

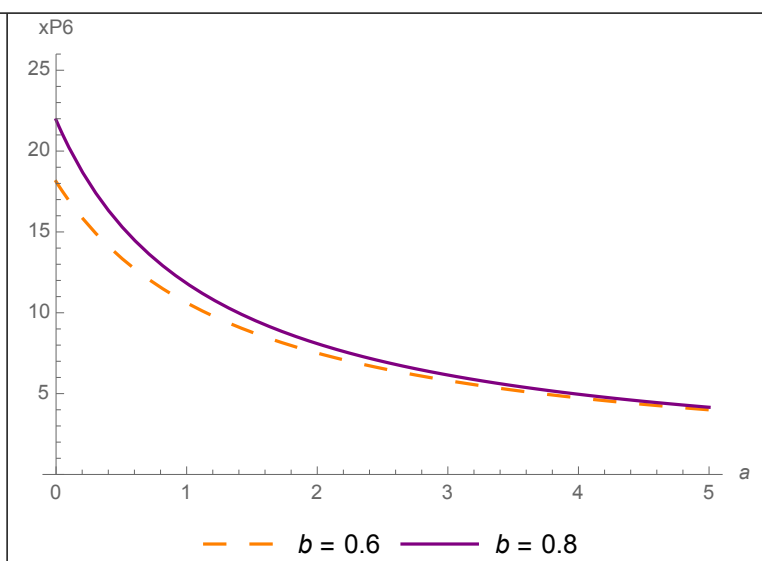

(ii) $H$ Proposer: proposer's pork in $H_{x y} H_{y} H_{y} H_{y} L_{y}$ proposal when $\alpha^{H}=0.6$

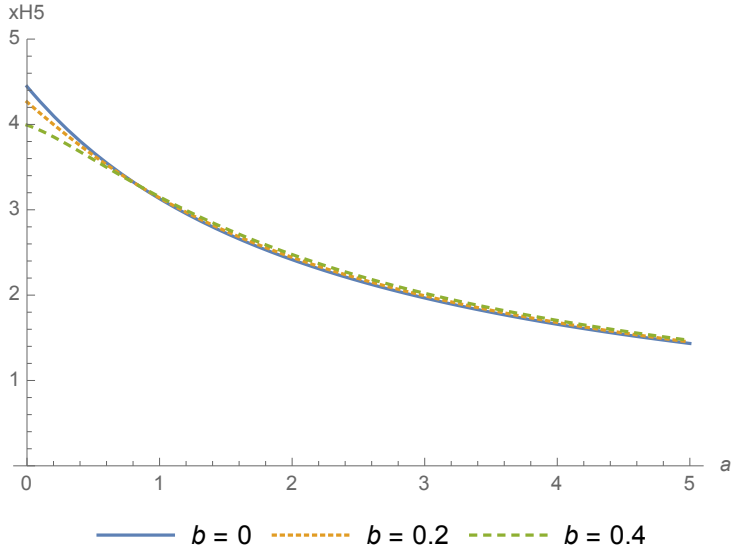

(iv) $H$ Proposer: $H$ coalition member's pork in $H_{x y} H_{x y} L_{y}$ proposal when $\alpha^{H}=0.6$

Notes: For $q=0.2, m=1$, and $\delta=0.8$. SSPE predictions in the VW model are where $a, b=0$. An $L$ proposer offers $y=50$, and an $H$ proposer proposes $H_{x y} H_{y} H_{y} H_{y} L_{y}$ when $\alpha^{H}=0.3$ or $\alpha^{H}=0.6$ and $b$ is large. When $b$ is small an $H$ proposer offers $H_{x y} H_{x y} L_{y}$. 